\title{
Tick-Borne Fever in Lambs of Different Ages
}

\author{
By S. Stuen
}

State Veterinary Research Station for Small Ruminants, Sandnes, Norway.

\begin{abstract}
Stuen, S.: Tick-borne fever in lambs of different ages. Acta vet. scand.1993, 34, 45-52. Four groups of lambs aged 1 week, 4 weeks, $1 / 2$ year and 1 year old respectively were inoculated with Ehrlichia phagocytophila infected blood. Clinical signs, temperature reactions, haematological changes and parasitaemia were more moderate in lambs inoculated with $E$. phagocytophila at the age of 1 week than those recorded in the older animals. The clinical response to tick-borne fever (TBF) appears to be more severe with increasing age of the lambs. The lymphocyte reactivity to mitogens was reduced in the TBF infected lambs, and was most pronounced in lambs in the 3 older age groups.
\end{abstract}

ehrlichia; sheep; lymphocyte transformation.

\section{Introduction}

Young animals are reported to react to an Ehrlichia phagocytophila infection with milder clinical reactions than older animals (McEwen 1947, Jamieson 1947, Tuomi 1967). A recent investigation by Stuen et al. (1992) has shown that the clinical reactions to tick-borne fever (TBF) in 2-week old lambs were milder than in 6-week old lambs. In addition, lymphocyte blastogenesis has been demonstrated to be suppressed in lambs infected with $E$. phagocytophila at the age of 3 weeks (Stuen et al. 1990). The present experiment was performed to further investigate the clinical response and lymphocyte reactivity to TBF in lambs of different ages.

\section{Materials and methods}

The material comprised 4 age groups of lambs: 1 week (Group 1), 4 weeks (Group 2), $1 / 2$ year (Group 3) and 1 year (Group 4). None of the animals had previously been on Ixodes ricinus infected pasture. Each group comprised a total of 16 lambs of the Dala and Rygja breeds. Lambs in Groups 1 and 2 were twins.

Eight lambs in each group were inoculated intravenously with $2 \mathrm{ml}$ of a whole blood dime- thyl sulphoxide stabilate (Foggie et al. 1966) of a TBF- strain isolated from a local sheep flock, while the remainder served as controls. In Groups 1 and 2, single twins were inoculated. Rectal temperatures were measured once daily for at least 3 weeks starting on the day of inoculation (Day 0). Incubation period, duration of fever and magnitude of fever were recorded as previously described (Stuen et al. 1992). All animals were kept indoors during the experiment. Lambs in Groups 1 and 2 were kept with their dams whereas the older lambs were fed hay, silage and concentrates.

The lambs in Groups 1 and 2 were weighed weekly, and their daily weight gains for the 9 week experiment were calculated.

Heparinized blood samples were collected on days $0,7,14,28,42$ and 63 post-inoculation for measuring mitogen-induced lymphocyte transformation (LTT). Blood samples were also collected daily during the fever period. The blood samples were collected at the same $\mathrm{h}$ in the morning from all animals in each group. Total and differential leucocyte counts were performed as previously described (Stuen et 
al. 1992). The percentage of parasitized neutrophil granulocytes was calculated.

The whole blood method for measuring LTT according to the method described by Larsen (1979) was used with some modifications. Briefly, the blood samples were diluted to a final concentration of $1 \cdot 10^{6}$ lymphocytes per $\mathrm{ml}$, with RPMI 1640 medium (Gibco, Scotland) supplemented with Hepes buffer (Gibco, Scotland) and adjusted to a pH between 7.2 and 7.4. The culture medium also contained penicillin (100 units $/ \mathrm{ml})$, streptomycin $(100 \mu \mathrm{g} / \mathrm{ml})$ and L-glutamine $(30 \mathrm{mg} / \mathrm{ml})$. Cultures were made in flatbottomed plastic microtitre plates (Nunc, Denmark) with $0.2 \mathrm{ml}$ of the diluted blood per well. Each well received $20 \mu \mathrm{l}$ of mitogens. Four wells were used for each sample and each control. Cultures were incubated for a total of 68 $\mathrm{h}$ at $37^{\circ} \mathrm{C}$ in a humidified atmosphere containing $5 \% \mathrm{CO}_{2}$ in air.

The following mitogens were used: phytohaemagglutinin (PHA)(Gibco Laboratories, USA), poke weed mitogen (PWM)(Gibco Laboratories, USA) and concanavalin A (ConA)(Sigma Chemical Company, USA). Effects of varying concentration of the mitogens were examined in preliminary tests. In subsequent tests, 60 $\mu \mathrm{l} / \mathrm{ml}$ of PHA, $60 \mu \mathrm{l} / \mathrm{ml}$ of PWM and $60 \mu \mathrm{g} / \mathrm{ml}$ of ConA were used. Stock solutions of mitogens were stored at $-20^{\circ} \mathrm{C}$ in suitable aliquots.

The synthesis of DNA by peripheral blood lymphocytes was determined by measuring the incorporation of $\left({ }^{3} \mathrm{H}\right)$-thymidine (specific activity $185 \mathrm{GBq} / \mathrm{mmol}$, Amersham, U.K.). Standard labelling was carried out by adding $1 \mu \mathrm{Ci}$ of $\left({ }^{3} \mathrm{H}\right)$ thymidine in $10 \mu$ l of RPMI 1640 to each culture $21 \mathrm{~h}$ before terminating incubation. The plates were then stored at $-20^{\circ} \mathrm{C}$. For harvesting, the cultures were thawed and the cells transferred onto glass fibre filter paper discs (Filtermats 7031, Skatron, Norway) with a semi-automatic multiple cell culture harvester (Skatron, Norway). The filter discs were dried and transferred to scintillation vials containing $2.5 \mathrm{ml}$ scintillation fluid (Opti-fluor O, Packard, USA). The thymidine incorporation was measured with an automatic liquid scintillation counter (1500 Tricarb, Packard, USA).

All results were $\log _{10}$ transformed because of the variation in the cpm (counts per min) within each group. The response was calculated in all groups as a stimulation index $\left(\mathrm{SI}_{\mathrm{log}}\right)$ :

$\mathrm{SI}_{\log }=\left(\right.$ mean $\mathrm{cpm}_{\log }$ in cultures with mitogen $)$ - (mean $\mathrm{cpm}_{\log }$ in cultures without mitogen)

Table 1. Mean and standard deviation (std) of different clinical variables in Ehrlichia phagocytophila infected lambs in 4 different age groups, 1 week, 4 weeks, $1 / 2$ year and 1 year old, respectively.

\begin{tabular}{|c|c|c|c|c|c|c|c|c|}
\hline & \multicolumn{2}{|c|}{$\begin{array}{c}1 \text { Week } \\
\mathrm{n}=8\end{array}$} & \multicolumn{2}{|c|}{$\begin{array}{c}4 \text { Weeks } \\
n=8\end{array}$} & \multicolumn{2}{|c|}{$\begin{array}{c}1 / 2 \text { Year } \\
n=8\end{array}$} & \multicolumn{2}{|c|}{$\begin{array}{c}\text { 1Year } \\
n=8\end{array}$} \\
\hline & Mean & Std & Mean & $S t d$ & Mean & $S t d$ & Mean & Std \\
\hline $\begin{array}{l}\text { Incubation } \\
\text { period (days) }\end{array}$ & 4.8 & 0.89 & 3.4 & 0.52 & 3.0 & 0.00 & 3.0 & 0.00 \\
\hline $\begin{array}{l}\text { Maximum } \\
\text { temp }\left({ }^{\circ} \mathrm{C}\right)\end{array}$ & 41.4 & 0.30 & 41.7 & 0.18 & 41.4 & 0.20 & 42.1 & 0.14 \\
\hline $\begin{array}{l}\text { Duration of } \\
\text { fever (days) }\end{array}$ & 5.3 & 1.58 & 4.8 & 1.28 & 6.1 & 0.64 & 6.5 & 2.56 \\
\hline $\begin{array}{l}\text { Magnitude of } \\
\text { fever }\left(\mathrm{mm}^{2}\right)^{*}\end{array}$ & 5168 & 1469 & 5892 & 1365 & 5314 & 420 & 8308 & 2108 \\
\hline
\end{tabular}

*The magnitude of fever is calculated as the area under the temperature curve with $40^{\circ} \mathrm{C}$ as base line. 


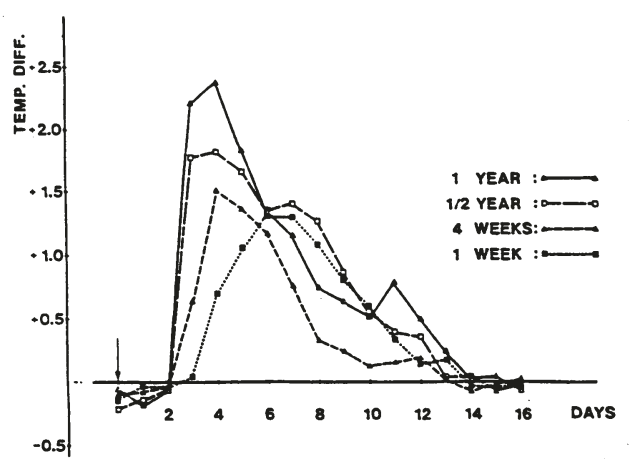

Figure 1. Mean temperature differences $\left({ }^{\circ} \mathrm{C}\right)$ on days post-inoculation between Ehrlichia phagocytophila infected lambs and controls in 4 age groups: 1 week, 4 weeks, $1 / 2$ year and 1 year old, respectively. The inoculation time is indicated with an arrow $(\downarrow)$.

Student's t-test was used in statistical calculations, and statistical comparison was only made between inoculated and control lambs within each group.

\section{Results}

All lambs that were inoculated reacted with elevated body temperature. The mean temperature reactions are recorded in Table 1.

The clinical signs were conspicuous in the 2 old- er age groups, with 3-4 days of dullness and inappetence, whereas no clinical signs were recorded in lambs in Groups 1 and 2. Three lambs in the control groups, 1 in Group 1 and 2 in Group 4, were found to be infected with Eperythrozoon ovis on the first day of sampling (Day 0) and were therefore excluded from the experiment. Another control lamb in Group 1 died of E.coli septicaemia.

The largest temperature differences between inoculated and control lambs were recorded on the second day of fever (Day 4) in lambs in Groups 2, 3 and 4 (Fig.1). In Group 1, the largest temperature difference was observed on Day 6.

The percentages of parasitized neutrophil granulocytes were less in lambs in Group 1 than in the other groups on Day 3, 4 and 5 (Fig.2).

The number of lymphocytes was reduced during the febrile period of TBF in all groups, and was most pronounced in lambs in Groups 2, 3 and 4 . The difference in the number of lymphocytes between inoculated and control lambs was statistically significant on: Day $5(\mathrm{p}<0.005)$ in Group 1, Day 4-8 $(\mathrm{P}<0.025)$ in Group 2 and Day 3-8 $(\mathrm{p}<0.005)$ in Groups 3 and 4.

Table 2. The number of neutrophil granulocytes (G/1) in TBF inoculated lambs in 4 different age groups (see Table 1). The lambs were inoculated with E. phagocytophila on Day 0.

\begin{tabular}{|c|c|c|c|c|c|c|c|c|}
\hline & \multicolumn{2}{|c|}{$\begin{array}{c}1 \text { Week } \\
n=8\end{array}$} & \multicolumn{2}{|c|}{$\begin{array}{c}4 \text { Weeks } \\
n=8\end{array}$} & \multicolumn{2}{|c|}{$\begin{array}{c}1 / 2 \text { Year } \\
n=8\end{array}$} & \multicolumn{2}{|c|}{$\begin{array}{c}1 \text { Year } \\
\mathrm{n}=8\end{array}$} \\
\hline & Mean & Std & Mean & Std & Mean & Std & Mean & Std \\
\hline DAY 0 & $2.3 \mathbf{A}$ & 0.98 & $1.1 \$$ & 0.26 & $1.6 \$$ & 1.12 & $1.2 \Delta$ & 0.61 \\
\hline DAY 7 & 2.2 & 0.97 & 1.7 & 0.76 & 1.8 & 0.81 & 1.5 & 1.53 \\
\hline DAY 8 & 1.3 & 0.86 & 0.4 & $0.12 \mathrm{nd}$ & 0.6 & $0.23^{*}$ & 0.6 & $0.39 * *$ \\
\hline DAY 10 & 0.5 & $0.28 \mathrm{nd}$ & 0.3 & $0.10 \mathrm{nd}$ & 0.4 & $0.22 \mathrm{nd}$ & 0.5 & $0.23 \mathrm{nd}$ \\
\hline DAY 14 & 0.3 & $0.11^{* * *}$ & 0.4 & $0.18^{* * *}$ & 0.6 & $0.30 * * *$ & 0.3 & $0.19 * * *$ \\
\hline DAY 28 & 0.7 & 0.55 & 0.8 & $0.27 * * *$ & 0.7 & $0.16^{* *}$ & 1.1 & 0.31 \\
\hline DAY 42 & 0.8 & 0.33 & 0.7 & $0.20 * *$ & 1.3 & 0.84 & 0.7 & $0.39 *$ \\
\hline DAY 63 & 1.2 & 0.63 & 2.0 & 0.87 & 0.9 & 0.31 & 0.8 & 0.37 \\
\hline
\end{tabular}

$\Delta$ : including 14 lambs, \$: including 16 lambs, nd: t-test was not done.

$* \mathrm{p}<0.05, * * \mathrm{p}<0.025, * * * \mathrm{p}<0.01$ 


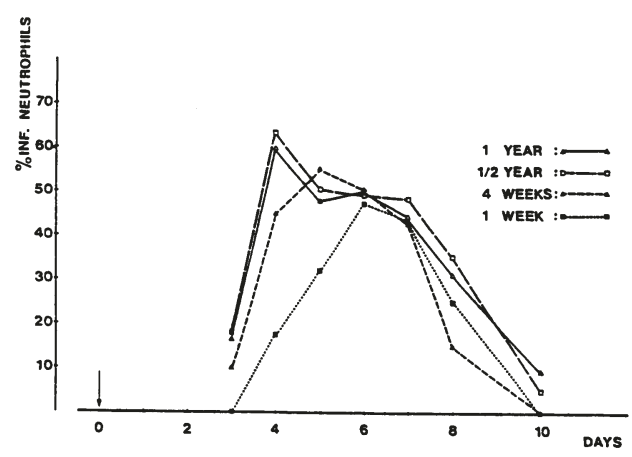

Figure 2. Mean percentage of neutrophil granulocytes infected with $E$. phagocytophila in lambs in different age groups.

All inoculated lambs were neutropenic $(<0.7 \mathrm{G} / \mathrm{l})$ on Day 10 and 14. Lambs in Groups 2, 3 and 4 were also neutropenic on Day 8 (Table 2).

The number of neutrophil granulocytes in the inoculated lambs remained low after the fever period. A difference in number of neutrophils between inoculated and control lambs was still present on Day 63 in the 2 older age groups (data not shown).

The weight gain of inoculated lambs was impaired in Groups 1 and 2. In the latter group, the difference between inoculated and control lambs was statistically significant $(\mathrm{p}<0.025)$ (data not shown).

The results from the lymphocyte transformation test, calculated as $\mathrm{SI}_{\mathrm{log}}$, are shown in Figs.3-5. The difference in $\mathrm{SI}_{\log }$ between inoculated (I) and control (C) lambs was statistically significant on the following days:

PHA: Group 1: Day 14, 42 (p<0.025), Group 2: Day 7, 14, 28 (p<0.005), Group 3: Day 7, 14, 42 $(\mathrm{p}<0.025)$ and Group 4: Day 7, 14, $28(\mathrm{p}<0.05)$, PWM: Group 3: Day 14, 42 ( $<<0.025)$

ConA: Group 1: Day 7, 14, 42 ( $\mathrm{p}<0.05)$, Group 2: Day 7, 14, 28 ( $\mathrm{p}<0.005)$, Group 3: Day 7, 14,

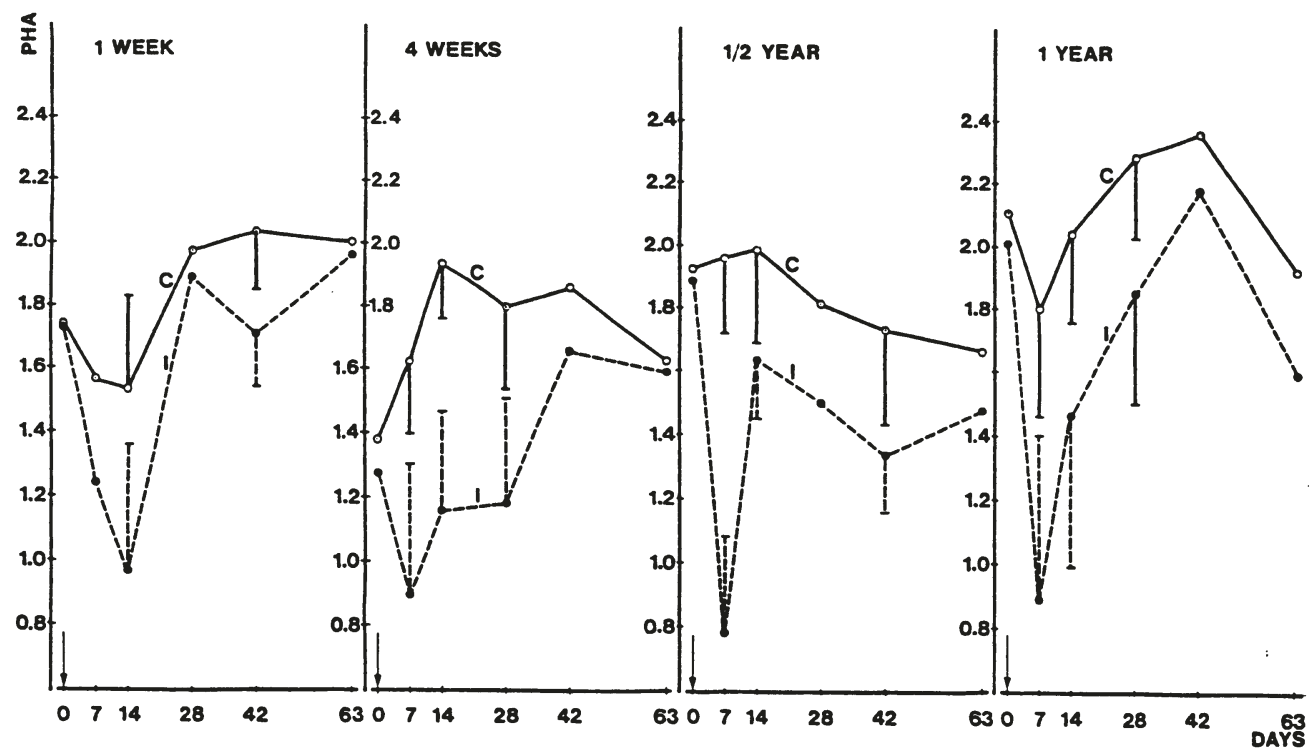

Figure 3. Response of peripheral lymphocytes to PHA measured as $\mathrm{SI}_{\log }$, in lambs of different ages. Vertical bars indicate the range of standard deviation. $\mathrm{SI}_{\log }=\left(\right.$ mean $\mathrm{cpm}_{\log }$ in cultures with mitogen $)-\left(\right.$ mean $\mathrm{cpm}_{\log }$ in cultures without mitogen) 


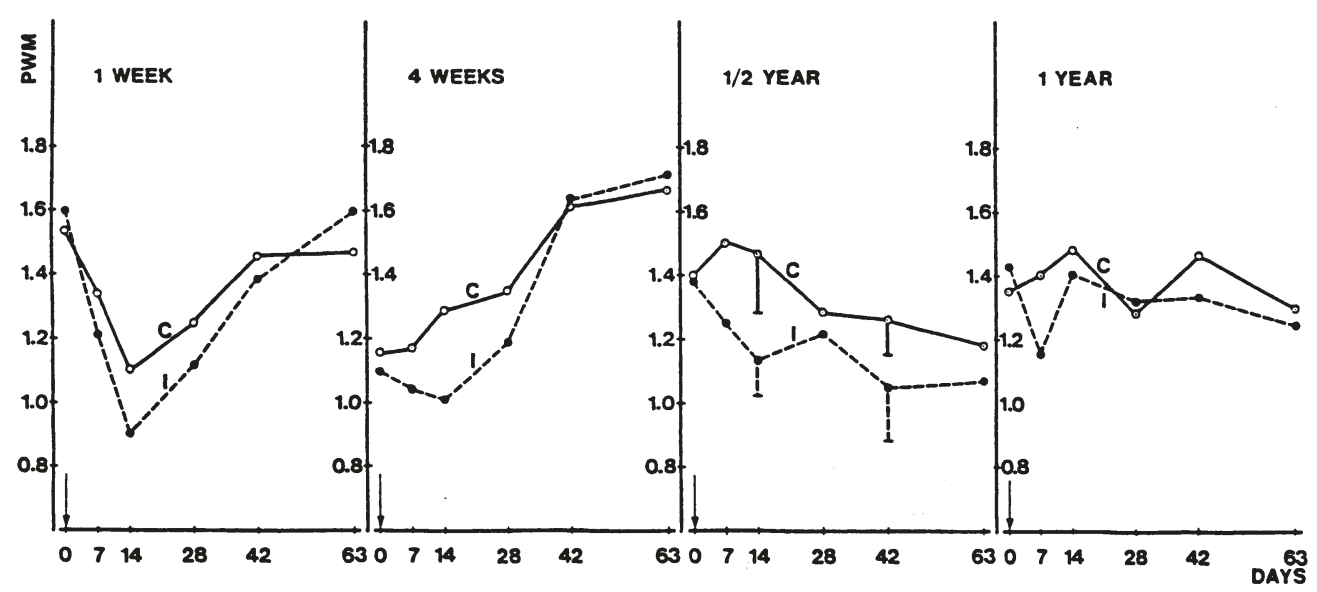

Figure 4. Response of peripheral lymphocytes to PWM measured as $\mathrm{SI}_{\log }$ (see Fig.3).

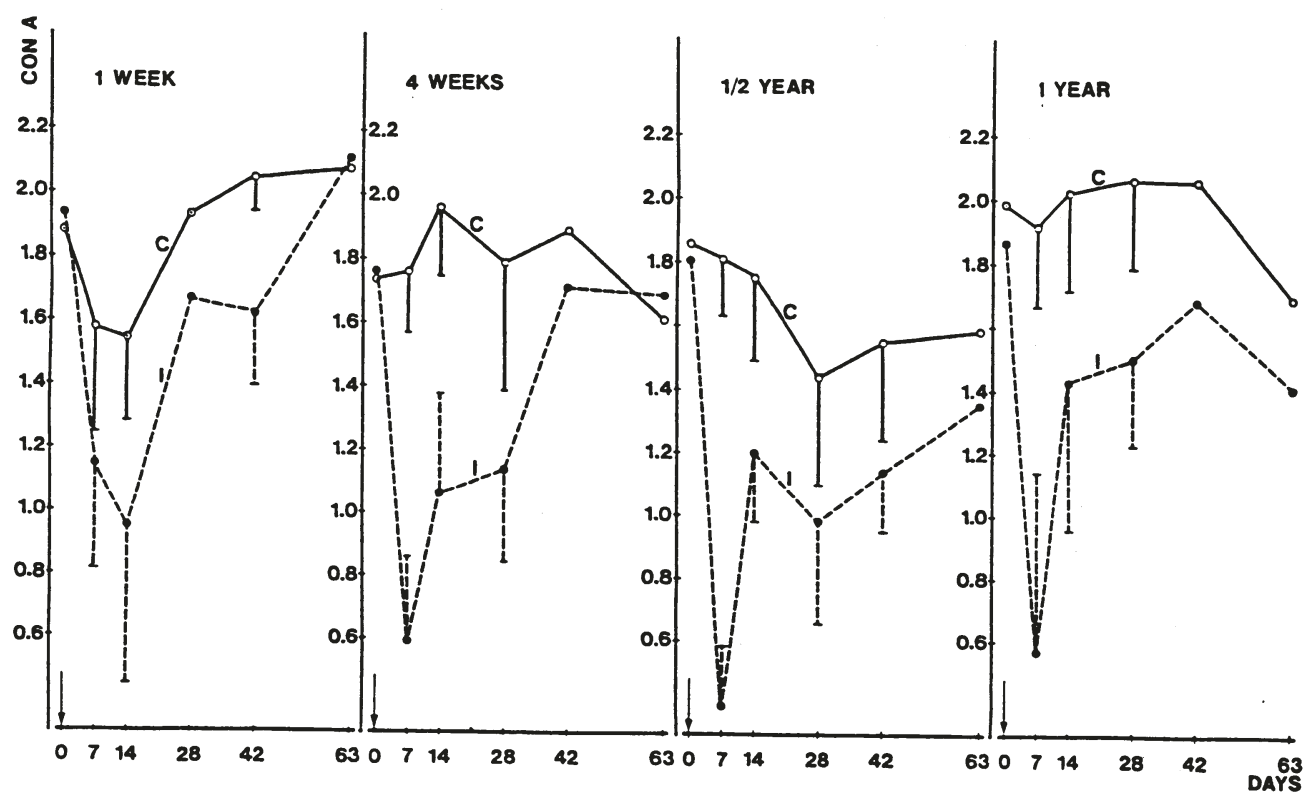

Figure 5. Response of peripheral lymphocytes to ConA measured as $\mathrm{SI}_{\log }$ (see Fig.3).

28, $42(\mathrm{p}<0.025)$ and Group 4: Day 7, 14, 28 $(\mathrm{p}<0.05)$.

In the PWM stimulated cells the cpm values in all groups tended to be lower than for the other 2 mitogens. One week after the TBF inocu- lation, the $\mathrm{SI}_{\log }$ fell in both PHA and ConA stimulated cells. The difference in $\mathrm{SI}_{\log }$ between inoculated and control lambs was most pronounced in ConA stimulated cells. In Group 1, the $\mathrm{SI}_{\log }$ fell in all mitogen stimulated lympho- 
cytes from both control and inoculated lambs during the first 2 weeks of sampling. In contrast, the $\mathrm{SI}_{\log }$ for the control lambs in Group 2 rose during the first 2 weeks of sampling in all mitogen stimulated lymphocytes.

\section{Discussion}

The results of the present study indicate that the severity of clinical response to TBF infection increases with increasing age of the lambs. The oldest lambs had the most pronounced temperature reactions and parasitaemia was most prominent in lambs of the 3 older groups.

Young lambs may receive TBF antibodies from their dams through colostrum. Serological tests were not performed in this study, so the influence of colostral antibodies on the clinical reactions of lambs in Groups 1 and 2 is unknown. However, as previously demonstrated, 2-week old lambs seem to be more resistant to TBF infection than 6-week old lambs, and this increased resistance appears to be due to factors other than TBF antibodies (Stuen et al. 1992).

The maximum temperature and the magnitude of fever in 6 months old lambs (Group 3) were less than those of 4 week old lambs (Group 2). However, the temperature differences between inoculated and control lambs in Group 3 were between those of Group 2 and Group 4 (1 year old). This discrepancy is difficult to explain. Lambs in Group 3 were infected with TBF in the autumn, while the other age groups were infected in the spring. The body temperatures were recorded at the same $h$ every day to eliminate diurnal variation (Bligh et al. 1965). However, Bligh et al. (1965) also observed that there may be a seasonal variation in body temperature in sheep on pasture.

A transient decrease in number of lymphocytes during a TBF infection has been demonstrated by Taylor et al. (1941) and Batungbacal et al. (1982). In the present experiment, a drop in number of lymphocytes was recorded only on a single day in lambs in Group 1, while decreased numbers were observed in the other groups for 5-6 days.

The number of neutrophil granulocytes on Day 0 was higher in 1 week old lambs than in the other groups. This agrees with observations made by Ullrey et al. (1965), who found that the number of neutrophil granulocytes in lambs decreases from the second week of life and throughout the first year.

Although observations were not made between Day 14 and Day 28, the period of neutropenia was apparently similar in all inoculated lambs. Observations by others have shown that neutropenia lasts for 1-3 weeks (Taylor et al. 1941, Foster \& Cameron 1970, Brodie et al. 1986). No difference in the degree of neutropenia was observed between the age groups in the present experiment.

A drop in the number of neutrophil granulocytes was present in all TBF infected lambs on Day 14. This reduction appeared earlier and was subtained longer in the 3 older age groups. In a previous experiment, a reduced number of neutrophil granulocytes was observed for more than 4 months in lambs inoculated with $E$. phagocytophila at the age of 3 weeks (Stuen et al. 1990).

Foggie (1951) observed that E. phagocytophila could survive for months in sheep. The agent was not found in the blood of a sheep 47 weeks after the primary infection, but reappeared in blood smears when the sheep was splenectomised in the 48th week. The reduction in number of neutrophil granulocytes in this study may be caused by destruction and sequestration of infected cells (Hudson 1950). Although the agent was not found in blood smears after the fever period, the extended period of reduced number of neutrophil granulocytes observed in the present study could indicate a prolonged lowgrade infection with E.phagocytophila. The question arises whether there may be differenc- 
es in survival time of E. phagocytophila in lambs of different ages.

The daily weight gain was significantly impaired in inoculated lambs in Group 2. No reduction in weight gain was found in Group 1. Sex and breed were equally distributed between inoculated and control lambs in both groups. This observation indicates that lambs inoculated at the age of 1 week may suffer less from TBF than those inoculated at the age of 4 weeks. The results from previous experiments (Stuen et al. 1992) indicated that the weight gain in lambs infected with E.phagocytophila at the age of 6 weeks was also significantly reduced.

In all mitogen stimulated cells the stimulation index decreased after TBF inoculation, and there was a pronounced difference in the $\mathrm{SI}_{\log }$ between inoculated and control lambs. Those results indicate that lambs in the older 3 groups had a more pronounced reaction to TBF infection than lambs in 1 week age group. However, the LTT results from the different age groups are difficult to compare. Firstly, the samples were collected at different times of the year, although the sampling $\mathrm{h}$ was the same. Evidence has been presented that there may be a seasonal variation in cell mediated immunity (Shifrine et al. 1980). Secondly, the normal LTT response in different age groups of lambs is unknown. For example, Soper et al. (1978) found an age-related PHA and ConA response in cattle.

Thirdly, when a whole blood technique is used variables that affect the blood may influence the result of the LTT, e.g. stress, hormonal changes, disease, exercise (Fiscus et al. 1982). In addition, depression of lymphocyte reactivity by granulocytes has been demonstrated. The release of toxic substances, mainly lytic enzymes from dead granulocytes, seems to be a possible explanation (Judson \& Dixon 1985).

The present experiment identified a reduced lymphocyte blastogenesis in PHA and ConA stimulated cells, that was most pronounced in lambs infected with E. phagocytophila at the age of 4 weeks. The small differences in the PWM stimulated cells are consistent with results obtained earlier (Zimmerman et al. 1984, Stuen et al. 1990).

A pronounced suppression of the lymphocytes in TBF infected sheep has also been observed by Larsen et al. (1986). They demonstrated severe suppression of the lymphocyte response to PHA, PWM and ConA up to 6 weeks after inoculation with E. phagocytophila. In addition, Woldehiwet (1987) measured the lymphocyte response to lipopolysaccharide (LPS) and PHA in TBF infected sheep and showed that both LPS and PHA responses were impaired during the first 2 weeks of the infection. According to Woldehiwet (1991) the number of both T- and B-lymphocytes were reduced during an $E$. phagocytophila infection. Further investigation using purified lymphocytes is needed to understand the reduced lymphocyte response in TBF infected sheep.

The clinical symptoms, haematological changes, lymphocyte suppression, parasitaemia and tempera- ture reactions were milder in 1 week old lambs than in older animals, an observation which indicates that 1 week old lambs are more resistant to infection with $E$. phagocytophila than older lambs. Further experiments are needed to confirm if this observed difference is due to innate resistance.

\section{Acknowledgement}

The study was supported by a grant from the Agricultural Research Council of Norway. The author thanks Dr. Charles Press for linguistic correction of the manuscript.

\section{References}

Batungbacal MR, Scott GR, Burrells C: The lymphocytopaenia in tick-borne fever. J. comp. Path. 1982, 92, 403-407.

Bligh J, Ingram DL, Keynes RD, Robinson SG: The deep body temperature of an unrestrained Welsh 
mountain sheep recorded by a radiotelemetric technique during a 12-month period. J. Physiol. 1965, 176, 136-144.

Brodie TA, Holmes PH, Urquhart GM: Some aspects of tick-borne diseases of British sheep. Vet. Rec. 1986, 118, 415-418.

Fiscus SA, DeMartini JC, Pearson LD: Variation in mitogen-induced ovine lymphocyte blastogenesis: Adherent cells or 2-mercaptoethanol restore randomly depressed responses. Vet. Imm. and Imm.path. 1982, 3, 345-359.

Foggie A: Studies on the infectious agent of tickborne fever in sheep. J. Path. Bact. 1951, 63, 1-15.

Foggie A, Lumsden WHR, McNeillage GJC: Preservation of the infectious agent of tick-borne fever in the frozen state. J. comp. Path. 1966, 76, 413-416.

Foster WNM, Cameron AE: Observations on ovine strains of tick-borne fever. J. comp. Path. 1970, 80, 429-436.

Hudson JR: The recognition of tick-borne fever as a disease of cattle. Brit. vet. J. 1950, 106, 3-17.

Jamieson S: Some aspects of immunity to tick-borne fever in hoggs. Vet. Rec. 1947, 59, 201-202.

Judson DG, Dixon JB: Depression of lymphocyte reactivity by granulocytes in equine whole blood culture. Vet. Imm. and Imm.path. 1985, 8, 289-295.

Larsen HJ: A whole blood method for measuring mitogen-induced transformation of sheep lymphocytes. Res. Vet. Sci. 1979, 27, 334-338.

Larsen HJ, Øvernes $G$, Waldeland H: Immuno-suppression caused by Ehrlichia phagocytophila in sheep. Scand. J. Imm. 1986, 24, 468.

McEwen $A D$ : Tick-borne fever in young lambs. Vet. Rec. 1947, 59, 198-201.

Shifrine M, Taylor N, Rosenblatt LS, Wilson F: Seasonal variation in cell mediated immunity of clinically normal dogs. Exp. Hemat. 1980, 8, 318-326.

Soper FF, Muscoplat CC, Johnson DW: In vitro stimulation of bovine peripheral blood lymphocytes: Analysis of variation of lymphocyte blastogenic response in normal dairy cattle. Amer. J. vet. Res. 1978, 39, 1039-1042.

Stuen S, Hardeng F, Larsen HJ: Resistance to tick- borne fever in young lambs. Res. Vet. Sci. 1992, 52, 211216.

Stuen S: Tick-borne fever in sheep. A clinical and immunological study. Dr.scient thesis, The Norwegian College of Veterinary Medicine, Oslo 1990.

Taylor AW, Holman HH, Gordon WS: Attempts to reproduce the pyaemia associated with tick-bite. Vet. Rec. 1941, 53, 337-344.

Tuomi J: Experimental studies on bovine tick-borne fever.(1). Clinical and haematological data, some properties of the causative agent, and homologous immunity. Acta path. microbiol. scand. 1967, 70, 429-445.

Ullrey DE, Miller ER, Long CH, Vincent BH: Sheep hematology from birth to maturity II. Leucocyte concentration and differential distribution. J. Anim. Sci. 1965, 24, 141-144.

Woldehiwet Z: Depression of lymphocyte response to mitogens in sheep infected with tick-borne fever. J. comp. Path. 1987, 97, 637-643.

Woldehiwet Z: Lymphocyte subpopulations in peripheral blood of sheep experimentally infected with tick-borne fever. Res. Vet. Sci. 1991, 51, 40-43.

Zimmerman GL, Isaacson Kerkvliet N, Brauner JA, Cerro JE: Ovine lymphocytes: Responses to mitogens using a whole blood technique. Int. goat sheep Res. 1984, 2, 114-121.

\section{Sammendrag \\ Tick-borne fever (Sjodogg) hos lam av ulik alder.}

Fire grupper av lam, henholdsvis 1 uke, 4 uker, $1 / 2$ år og 1 år gamle, ble podet med Ehrlichia phagocytophila infisert blod. Kliniske symtomer, tempteraturresponsen, hematologiske forandringer, samt parasittemien var mindre uttalt hos lam som ble podet når de var 1 uke gamle i forhold til lam i de $\emptyset$ vrige gruppene. De kliniske reasjoner på sjodogg syntes å øke med økende alder på lammene. Den mitogene lymfocyttresponsen var nedsatt hos sjodogginfiserte lam, mest uttalt hos lam i de 3 eldste gruppene.

(Received July 7, 1992; accepted November 13, 1992)

Reprints may be requested from: S. Stuen, Centre of Veterinary Medicine, N-9005 Troms $\varnothing$, Norway. 